\title{
Primary culture of capillary endothelial cells from the spiral ligament and stria vascularis of bovine inner ear
}

\section{Retention of several endothelial cell properties in vitro}

\author{
P.D. Bowman ${ }^{1}$, K. Rarey ${ }^{2}$, C. Rogers ${ }^{3}$, and G.W. Goldstein ${ }^{1}$ \\ ${ }^{1}$ Department of Pediatrics, University of Michigan, Ann Arbor, MI, USA; \\ ${ }^{2}$ Department of Anatomy, University of Florida, Gainesville, FL, USA; \\ ${ }^{3}$ Department of Anatomy, University of Michigan, Ann Arbor, MI, USA
}

\begin{abstract}
Summary. Methods for isolation and culture of microvascular endothelial cells of the inner ear were devised to provide an in-vitro system for studying endothelial functions in this tissue. Capillaries from the stria vascularis and spiral ligament were treated enzymatically to free them from surrounding tissue. Contamination by extraneous tissue was minimized by banding capillary segments in Percoll gradients and culture in plasma-derived serum on a fibronectin-coated substrate. Although only small amounts of inner ear tissue were available, tritiated thymidine autoradiography demonstrated that considerable growth in culture was possible. Addition of heparin and endothelial cell growth supplement to the medium enhanced proliferation. The endothelial origin of the cultured cells was confirmed by immunofluorescent demonstration of the presence of Factor VIII-related antigen and angiotensin-converting enzyme. In addition, tight junctions between cells were observed in both thin sections and platinum replicas obtained by freezefracture techniques. Endothelial cells from neither the stria vascularis nor the spiral ligament allowed passage of horseradish peroxidase across the monolayer during a 5 -min period. However, endothelial cells from the stria vascularis exhibited a greater amount of pinocytotic activity than those of the spiral ligament, a difference that is also observed in vivo. Methods for expanding a small population of endothelial cells with retention of specialized properties into one of sufficient size for morphologic and biochemical studies have been demonstrated for the inner ear.
\end{abstract}

Key words: Inner ear (bovine) - Endothelial cells - Cell culture - Tight junctions - Freeze-fracture

Although endothelial cells of capillaries probably comprise the most numerous cell type in the mammalian body, their small size and general unavailability in pure form make it difficult to study the metabolism of this cell type. Furthermore, it is likely that endothelial cells from different capillary beds have specialized properties which require independent examination. In the case of an organ such as the inner ear, they comprise only a small population of the tissue and are available in only small amounts. Cell culture offers an opportunity to study the endothelial cell in isolation

Send offprint requests to: Phillip D. Bowman, University of Michigan Medical Center, R6060, Kresge Research II, Ann Arbor, MI, 48109, USA and under relatively defined conditions, and to expand a small population of cells to a size large enough to perform morphologic and biochemical studies. While considerable success has been achieved in the isolation and culture of large vessel endothelial cells (Jaffe et al. 1973a; Gimbrone et al. 1974; Ryan et al. 1978), similar success has not been routinely attained with capillary endothelial cells. In fact, each type of capillary endothelial cell, depending on its source, may have special requirements for growth in vitro (Zetter 1981).

In this report we describe the isolation, cultivation and characterization of capillary endothelial cells from two regions of bovine inner ear, the spiral ligament and stria vascularis, both of which are richly provided with microvessels. Although these two microvasculatures are contiguous, they can be dissected so that there is almost no contamination by each other or by larger vessels. The microvasculature of the stria vascularis provides one of the few examples in mammals of a vascularized epithelium; the strial epithelium does not synthesize a basal lamina separating itself from its blood supply. In addition, the strial microvessels exhibit greater amounts of vesicular transport than do microvessels from the spiral ligament (Duvall et al. 1971), which may reflect a unique relationship between the strial epithelium and its capillaries with regard to the production of endolymphatic fluid. The microvessels of the spiral ligament, on the other hand, are often compared to cerebral capillaries in that they do not allow transcellular passage of protein and exhibit little pinocytotic ability.

By modification and refinement of methods utilized for preparation of endothelial cells from bovine adrenal gland (Folkman et al. 1979), brain (Bowman et al. 1981) and retina (Bowman et al. 1982), relatively pure populations of endothelial cells from the spiral ligament and stria vascularis were obtained in the present study. Under appropriate culture conditions, these endothelial cells exhibited considerable growth, and several of their in vivo properties were maintained in vitro.

\section{Materials and methods}

Temporal bone specimens were removed from the base of bovine skulls within two hours of death with an oscillating bone plug cutter after the brain was removed. Under a dissecting microscope, each temporal bone was drilled with a dental engine until the cochlea of the inner ear bony 
labyrinth was identified. Cold phosphate buffered saline solution was dripped on the bony cochlea to remove bone dust contamination as it was drilled. Each turn of the bony cochlear wall (containing the spiral ligament and stria vascularis) was separated from the organ of Corti, removed and placed in a sterile petri dish containing culture medium. The stria vascularis was then gently peeled away from the spiral ligament tissue with fine forceps under a dissecting microscope. Isolated spiral ligament and stria vascularis tissues from four bovine cochleas were pooled. Five to ten $\mathrm{mg}$ of stria vascularis and $25-35 \mathrm{mg}$ of spiral ligament (wet weight) were usually obtained from four inner ears.

The tissue culture medium used for enzyme treatment and culture was alpha Minimal Essential Medium (alpha MEM, Gibco, Long Island, N.Y.) containing $30 \mathrm{mM}$ Hepes buffer (Sigma Chemical Co., St. Louis, MO) at pH 7.4 and the following antibiotics: 25 units $/ \mathrm{ml}$ penicillin, $25 \mu \mathrm{g} / \mathrm{ml}$ streptomycin and $2.5 \mu \mathrm{g} / \mathrm{ml}$ Fungizone (Gibco). Strial endothelial cells were isolated by treatment with $1.0 \mathrm{mg} / \mathrm{ml}$ of a mixture of collagenase and dispase (Boehringer Mannheim, Indianapolis, IN) in alpha MEM. Spiral ligament endothelial cells were isolated by treatment with $5.0 \mathrm{mg} / \mathrm{ml}$ collagenase (Type IV, Sigma) for $3 \mathrm{~h}$. At the end of the dissociation period, the tissues were centrifuged at $800 \mathrm{Xg}$ for $5 \mathrm{~min}$ and the pellet resuspended in $1 \mathrm{ml}$ of medium and loaded onto a $10 \mathrm{ml}$ preformed $50 \%$ Percoll gradient prepared as described by Bowman et al. (1981). One ml fractions were collected and placed into a 12 well multiplate and the fraction containing the clumps of endothelial cells, usually the sixth fraction, was washed with medium containing $10 \%$ plasma-derived serum. Initially, plasma-derived serum was prepared as described by Bowman et al. (1982). Recently, however, horse plasma-derived serum has become available from Hyclone (Logan, Utah) and is now being used. The small, barely visible pellet of cells was resuspended in this medium and plated onto fibronectin-coated tissue culture dishes or polystyrene coverslips (Lux Scientific) as described earlier (Bowman et al. 1982). In some cases the cells were plated in medium containing $10 \%$ fetal calf serum (Hyclone).

To date, 35 attempts at cultivation of bovine inner ear endothelial cells have been made. In our early work, the presence of endothelial cells was always evident, but overgrowth by cells which did not exhibit endothelial markers hampered the usefulness of these cultures. Adventitious cell contamination has since been reduced by banding the endothelial cells in Percoll gradients and growing them in a selective medium. Morphologically pure cultures of endothelial cells are now routinely obtained.

\section{Immunofluorescence}

Identification of cells possessing Factor VIII-related antigen was performed essentially as described by Jaffe et al. (1973b). Rabbit antiserum to human Factor VIII-related antigen was obtained from Behring Diagnostics (La Jolla, $\mathrm{CA}$ ) and fluorescein conjugated goat antirabbit $\mathrm{IgG}$ was purchased from Cappel Laboratories (Cochranville, PA). A monoclonal antibody to angiotensin converting enzyme was kindly supplied by Dr. Robert Auerbach (Auerbach et al. 1982) and was used at a 1:100 dilution. Fluorescein conjugated rabbit anti-mouse antibody was obtained from Cappel Laboratories. Control ascites fluid (also from Cappel) was used as a negative control.

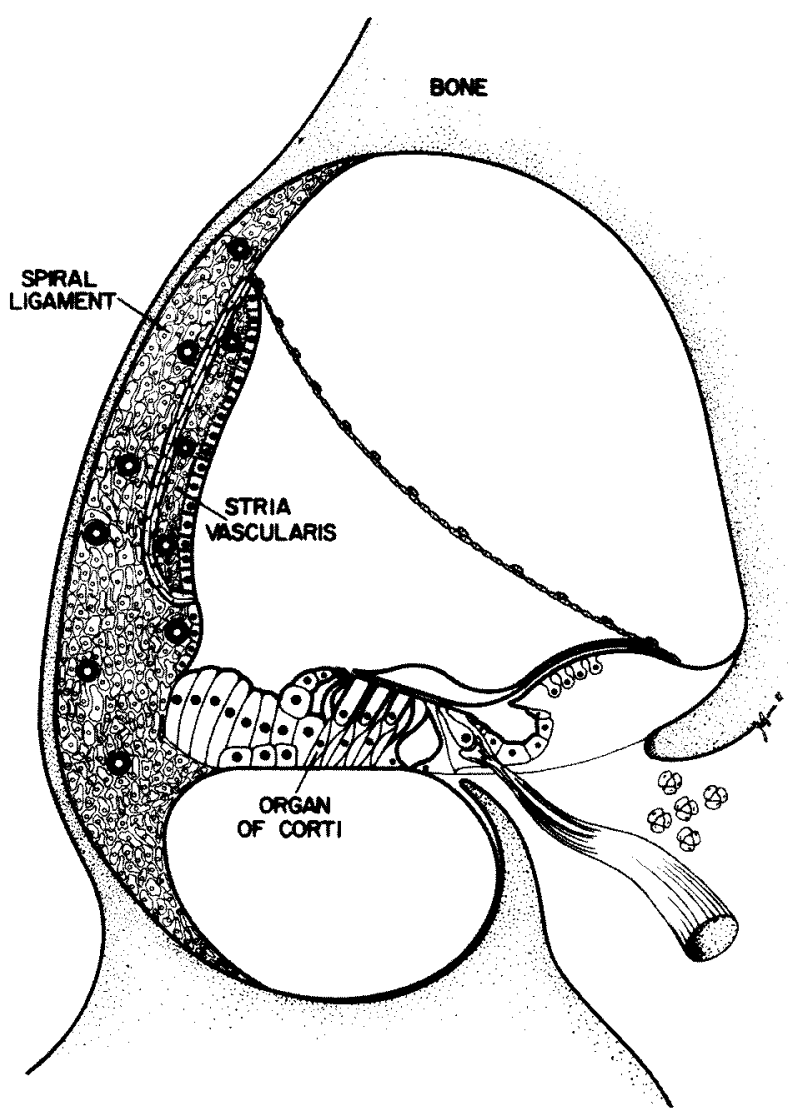

Fig. 1. Diagram of a section through the cochlear duct. Cells of the stria vascularis and spiral ligament form the lateral cochlear wall. The stria vascularis is separated from the spiral ligament by strial basal cells

\section{Autoradiography}

Tritiated thymidine autoradiography was used to determine the extent of endothelial cell growth that occurred in culture. Cells on polystyrene coverslips were labeled for $4 \mathrm{~h}$ with $1 \mu \mathrm{Ci} / \mathrm{ml}$ tritiated thymidine (New England Nuclear, Boston, $\mathrm{MA}, 60 \mathrm{Ci} / \mathrm{mM}$ ), fixed in $2.5 \%$ glutaraldehyde in phosphate buffered saline, rinsed twice with $70 \%$ ethanol and then overnight in running tap water. Coverslips were mounted cell side up and coated with NTB-2 emulsion (Kodak, Rochester, NY.). After exposure for 1 week, the slides were developed in D19 developer, fixed and stained with Giemsa.

\section{Transmission electron microscopy}

Cells for transmission electron microscopy were grown on fibronectin coated polystyrene coverslips or 12 well multiplates (Costar, Cambridge, MA). Following removal of the medium, the monolayers were washed twice with phosphate buffered saline, then fixed in $2 \%$ paraformaldehyde $/ 2.5 \%$ glutaraldehyde in $0.17 \mathrm{M}$ cacodylate buffer, $\mathrm{pH} 7.2$ for at least $1 \mathrm{~h}$. Studies of the movement of horseradish peroxidase (HRP) across the monolayer were carried out according to Dorovini-Zis et al. (1984). The cultured cells were washed three times with serum-free medium and then incubated at room temperature in medium containing $1 \mathrm{mg} / \mathrm{ml}$ of HRP (Type VI, Sigma) for $5 \mathrm{~min}$. This medium was 

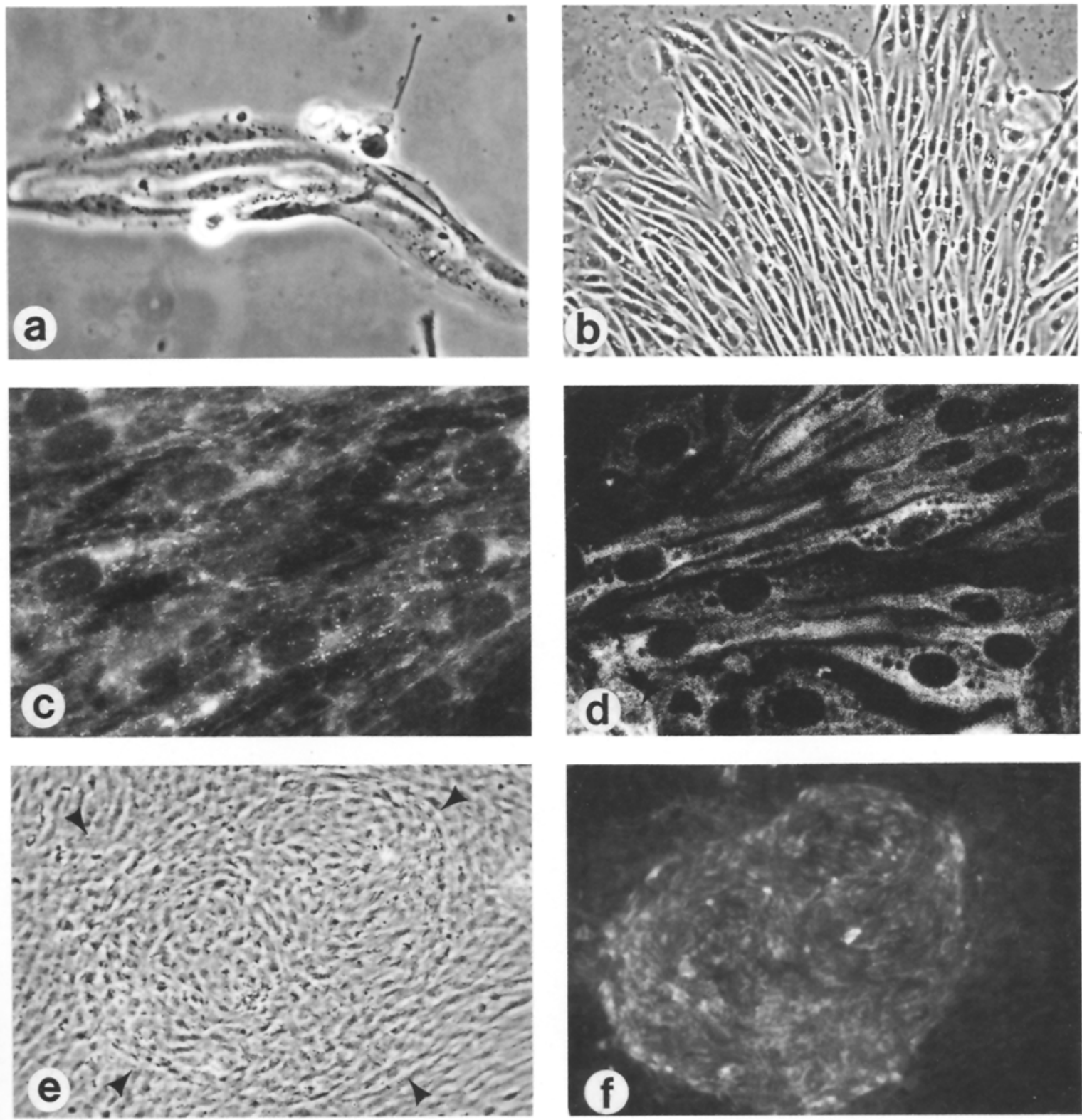

Fig. 2. a Phase-contrast micrograph of a group of spiral ligament endothelial cells at 3 days in culture. $\times 375$. b Phase micrograph of cultured spiral ligament endothelial cells at 2 weeks of culture, demonstrating that considerable growth has occurred. $\times 125$. $\mathrm{c}$ Indirect immunofluorescence staining for Factor VIII-associated antigen with rabbit anti-human Factor VIII. The granular, perinuclear immunofluorescence is indicative of the cells' endotheliall origin. This view is toward the center of an endothelial island where the immunofluorescence was most intense. $\times 1150$. d Indirect inmunofluorescence staining for angiotensin converting enzyme. Spiral ligament endothelial cells. $\times 750$ e Phase-contrast micrograph of strial endothelial cells grown in $10 \%$ fetal calf serum. Several other morphological cell types of unknown origin have overgrown the endothelial cells, which are demarcated by arrows. $\times 215$. $f$ This is the same field as shown in Fig. 2c, but stained by indirect immunofluorescence for Factor VIII antigen. $\times 215$

removed and the cell layer was washed three times $(2 \mathrm{~min}$ each wash) with serum-free medium and the cells were fixed at room temperature as above. The fixed cells were then washed three times in phosphate buffered saline and incu-

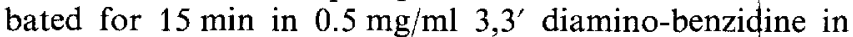
$0.1 \mathrm{M}$ Tris-HCL buffer, $\mathrm{pH} 7.6$, to permit histochemical identification of HRP complexes. Both HRP treated and untreated monolayers were washed with buffer and postfixed with $2 \%$ osmium tetroxide. After dehydration in graded concentrations of ethanol, cells were embedded in Epon/Araldite epoxy resin. Areas of cultured endothelial cells were cut from the embedded monolayers with a jew- elers' saw and reembedded in Epon/Araldite for thin sectioning and examination in a Philips 400 transmission electron microscope. In order to visualize HRP in the cells readily, the sections were not post-stained with lead citrate.

Quantitation of pinocytotic vesicles in the cultured endothelial cells was carried out by counting the number of HRP-containing vesicles per cell in 36 stria vascularis, and 37 spiral ligament, endothelial cells. Quantitation was performed at 12,500 $\mathrm{x}$ magnification, and only cells which could be viewed in their entirety were included. Student's $t$-test was used to compare the mean numbers of vesicles per cell in the two cell types. 


\section{Freeze-fracture of endothelial monolayers}

Cells grown on polystyrene coverslips were fixed with $2.5 \%$ glutaraldehyde in phosphate buffered saline $(\mathrm{pH} 7.2)$ for $1 \mathrm{~h}$ and then placed in $20 \%$ glycerol in phosphate buffered saline as described by Pauli et al. (1977). Areas for freezefracture were selected under an inverted microscope and were punched from the plastic coverslip with a $3 \mathrm{~mm}$ punch. The $3 \mathrm{~mm}$ disks were placed on the specimen carriers as described and rapidly frozen in a slurry of liquid nitrogen, placed in a double replicating device and transferred to liquid nitrogen for storage until placed in the freeze-fracture unit. The monolayers were fractured in a Balzers high vacuum freeze-fracture unit at $-115 \mathrm{C}$. Platinum-shadowed carbon replicas of the fractured faces were cleaned in Chlorox bleach for $24 \mathrm{~h}$. Subsequently, the replicas were rinsed in six changes of double distilled water, collected on HEX-400 grids (Polysciences, Warrington, PA) and examined in a Philips 400 electron microscope at $60 \mathrm{kV}$.

\section{Results}

The anatomy of the inner ear from which the capillary beds were derived is illustrated in Fig. 1. The spiral ligament and the stria vascularis form the lateral cochlear wall, which is perpendicular to the sensory and supporting cells of the organ of Corti. The predominant cell type of the spiral ligament is the fibroblast. The stria vascularis consists of four cell types: marginal epithelial, intermediate, basal, and endothelial. Because the microvessels of the spiral ligament are embedded in an extensive connective tissue matrix, it was determined that a more aggressive enzyme treatment $(0.5 \%$ collagenase) was required to free them than was required for the stria vascularis. The microvessel yield from the stria was considerably reduced when this dissociation procedure was applied to it, but cultures were successfully derived with a commercial preparation of collagenase and dispase $(0.1 \%)$. It was difficult to estimate the number of cells derived from each dissociation because of the small number of cells obtained. Usually, 50-100 islands, each covering approximately $0.25 \mathrm{~cm}^{2}$, were obtained by the end of 2 weeks from each capillary bed.

Figure 2 a shows a small capillary segment from the spiral ligament after 3 days in culture. At this point the cells have attached and migrated from the capillary tube, but growth has not yet become apparent. By two weeks, however, extensive islands of endothelial cells were formed (Fig. 2b). The endothelial origin of these cells is indicated by the presence of Factor VIII-associated antigen, as demonstrated in Fig. 2c. The granular, perinuclear fluorescence is most intense in the center of an endothelial cell island and becomes undetectable in cells at the edge of the island where proliferative activity is greatest. This suggests cell cycle specific regulation of Factor VIII-related antigen expression. The presence of angiotensin converting enzyme, an enzyme located on the surface of endothelial cells, is illustrated in Fig. $2 \mathrm{~d}$. No non-specific immunofluorescence was observed with nonimmune serum.

When microvessel segments from either spiral ligament or stria vascularis were plated in fetal calf serum, several other cell types (based on morphology under phase contrast microscopy) appeared, indicating that the enzymatic treatment had not completely removed all nonendothelial cell types. These other cell types quickly dominated the culture.
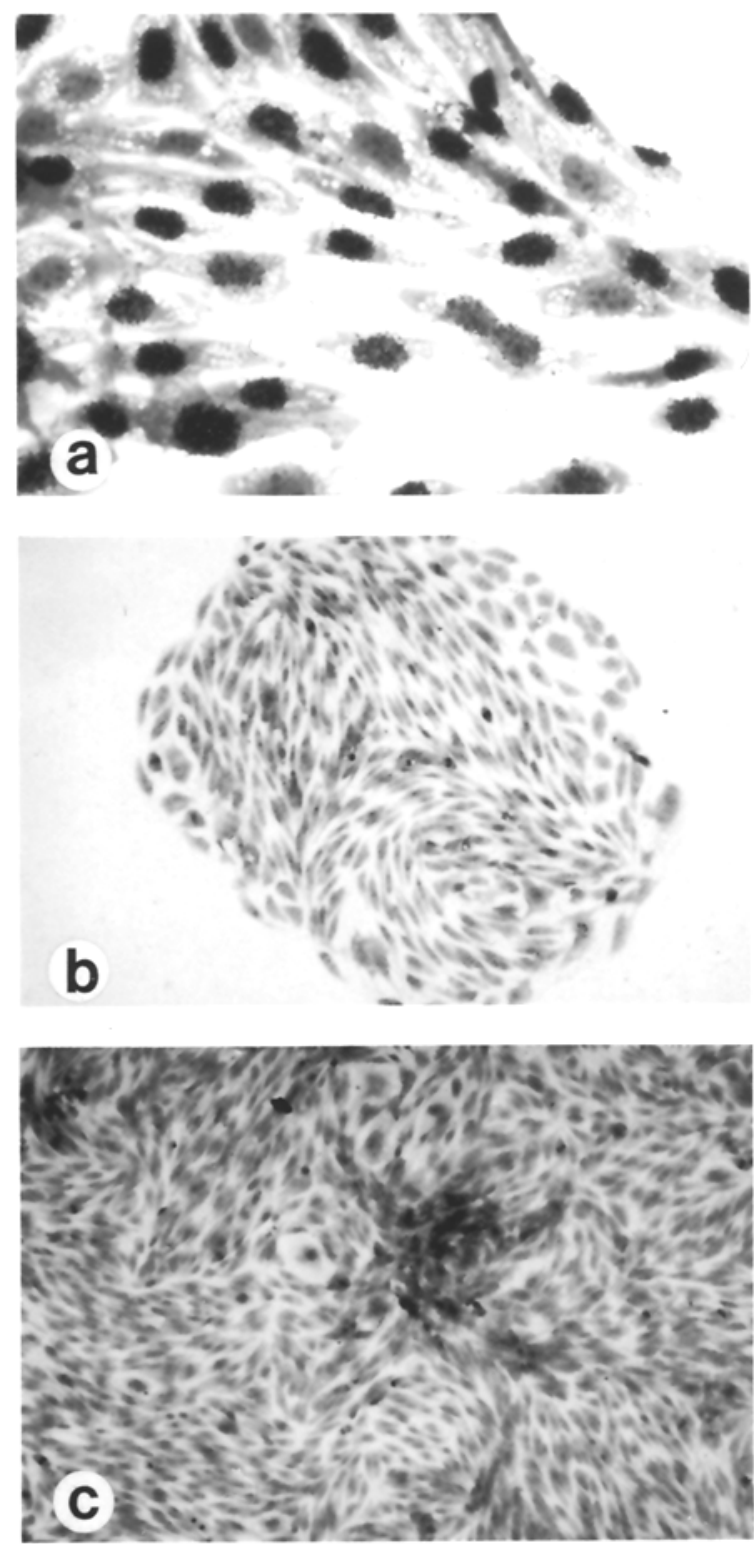

Fig. 3. a Light micrograph of an autoradiograph of an endothelial island at 10 days in culture. The large percentage of cells with nuclear incorporation of tritiated thymidine indicates the rapid rate of growth of which these endothelial cells are capable at this time. $\times 625$. b Light micrograph of an endothelial island at 2 weeks in culture in non-supplemented medium. $\times 125 . \mathbf{c}$ Light micrograph of an endothelial island set up as in Fig. $3 \mathrm{c}$ but in medium containing heparin $(100 \mu \mathrm{g} / \mathrm{ml})$ and endothelial growth supplement $(25 \mu \mathrm{g} /$ $\mathrm{ml})$. On the average, the size of these endothelial islands was twice that of the unsupplemented medium after the same time in culture. $\times 125$

Some of the cells were probably capillary pericytes. These have been cultured in calf serum by others (Gitlin and D'Amore 1983). Fig. 2e shows a phase contrast micrograph of microvessel cells from spiral ligament cultured in fetal calf serum. The spindle-shaped cells present a typical fibroblast morphology. The existence of endothelial cells in the culture, however, is illustrated in Fig. $2 \mathrm{f}$. This is the same area as in Fig. 2e as viewed in the fluorescence microscope after staining for anti-factor VIII-associated antigen. This result indicates that, while inner ear endothelial cells will grow in fetal calf serum, plasma-derived serum, which is 

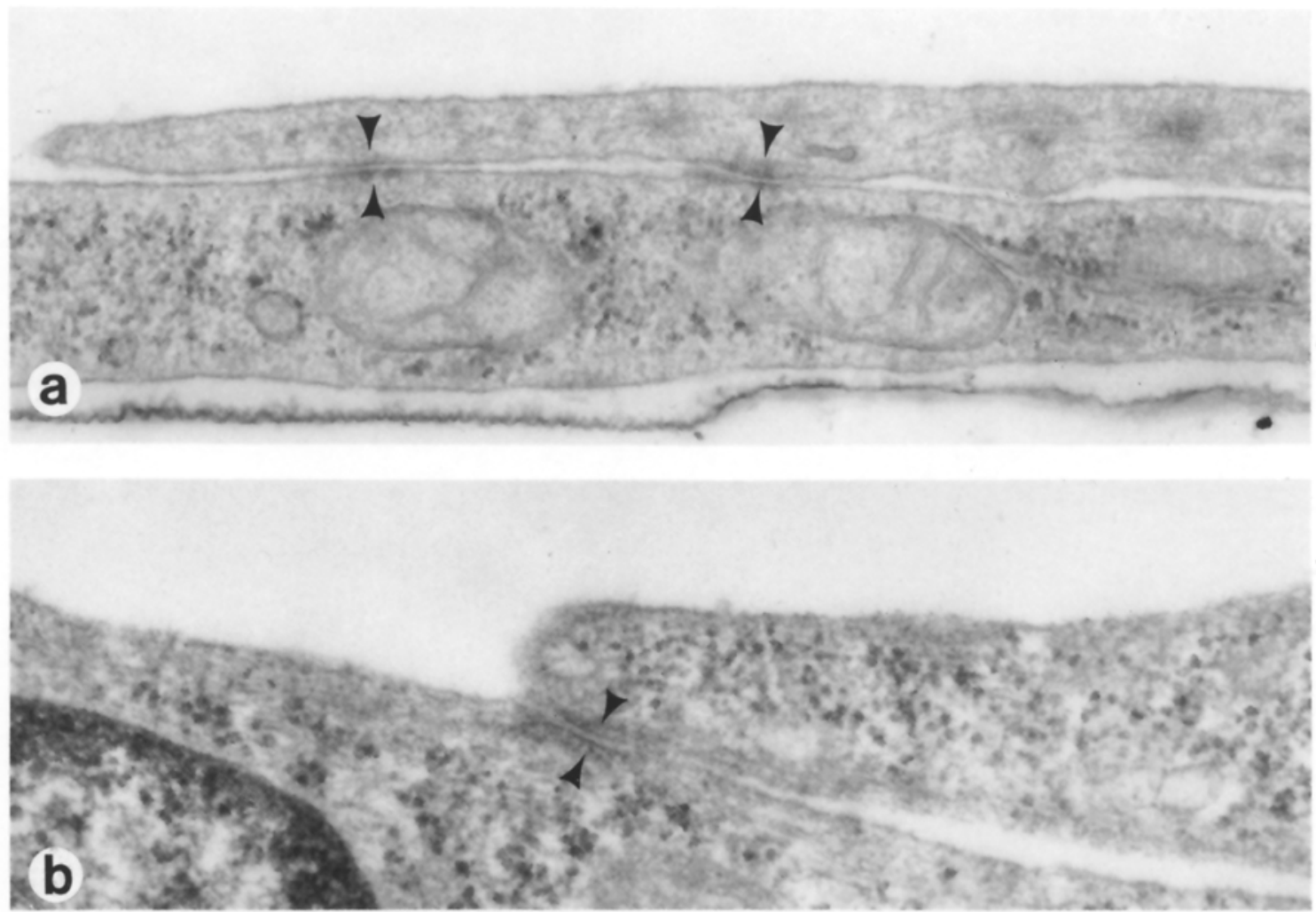

Fig. 4a, b. Electron micrograph of cultured (a) stria vascularis endothelial cells $(\times 14400)$ and (b) spiral ligament endothelial cells. $(\times 53750)$. Double arrows indicate regions of junctional complexes

poor in platelet-derived growth factor (Wall et al. 1978) is effective in eliminating contaminating cells which were not previously separated on the Percoll gradient. That considerable proliferative activity is possible by these cells is illustrated by the autoradiograph in Fig. $3 \mathrm{a}$. As many as $50 \%$ of the cells may incorporate tritiated thymidine during a four $\mathrm{h}$ labeling period at one week in culture. These results apply equally to endothelial cells obtained from the stria vascularis or spiral ligament.

In our most recent work, we have included heparin $(100 \mu \mathrm{g} / \mathrm{ml})$ and endothelial cell growth supplement $(20 \mu \mathrm{g} /$ $\mathrm{ml}$ ) in the culture medium, as described by Thornton et al. (1983). These additions result in endothelial cell islands that cover approximately twice the area as those cultured in their absence (Fig. 3b, c).

Perhaps the best marker for the endothelial origin of the cells was the presence of tight junctional complexes (Fig. 4). The characteristic behavior of these cells in producing overlapping regions between cells is apparent. This may explain their tendency to form islands of cells that remain in close contact at all times, even during proliferation. None of the other cells which proliferated in medium with fetal calf serum exhibited such a growth pattern or the presence of junctional complexes. Neither gap junctions nor WeibelPalade bodies, both characteristics of large vessel endothelial cells (Simionescu et al. 1975; Larsen and Sheridan 1979), were observed in the endothelial cells cultured from bovine inner ear.

Several features of the cultured capillary endothelial cells were demonstrated by freeze-fracture (Fig. 5). Morphologically, the cells are more fibroblast-like than epitheli- al-like and differ from large vessel endothelial cells in culture, which exhibit a more epithelial-like growth pattern. That the junctional complexes observed by transmission electron microscopy contained tight junctions was confirmed by freeze-fracture. Characteristic arrays of membrane particles occurred where two stria vascularis endothelial cells overlap a third. No differences could be detected in the morphology of the tight junctional complexes between stria vascularis and spiral ligament cultures. However, considerable variation in the complexity of the junctions among cells from the same culture was noted. This may be due to maturational differences associated with a population of cells at different stages of the cell cycle.

The ability of HRP to move across the junctional regions was tested, and it was found that no HRP normally moved across the barrier provided by either type of capillary endothelial cell. However, HRP was incorporated into pinocytotic vesicles, and more vesicles were present in cultured endothelial cells from stria vascularis than from spiral ligament. These data are illustrated in Fig. 6. The mean number of vesicles per stria vascularis endothelial cell was approximately 5 times that found per spiral ligament endothelial cell. These vesicles were most prevalent near the tight junctional complexes where the cells overlapped (Fig. 7a). Examination of freeze-fracture replicas for indications of pinocytosis suggested, again, that more pinocytotic vesicles were present in endothelial cells from stria vascularis (Fig. $7 \mathrm{~b}$ ) than spiral ligament. Other than this, no significant differences in morphology were observed between the two types. Neither gap juctions nor Weibel-Palade bodies were observed in the replicas. 

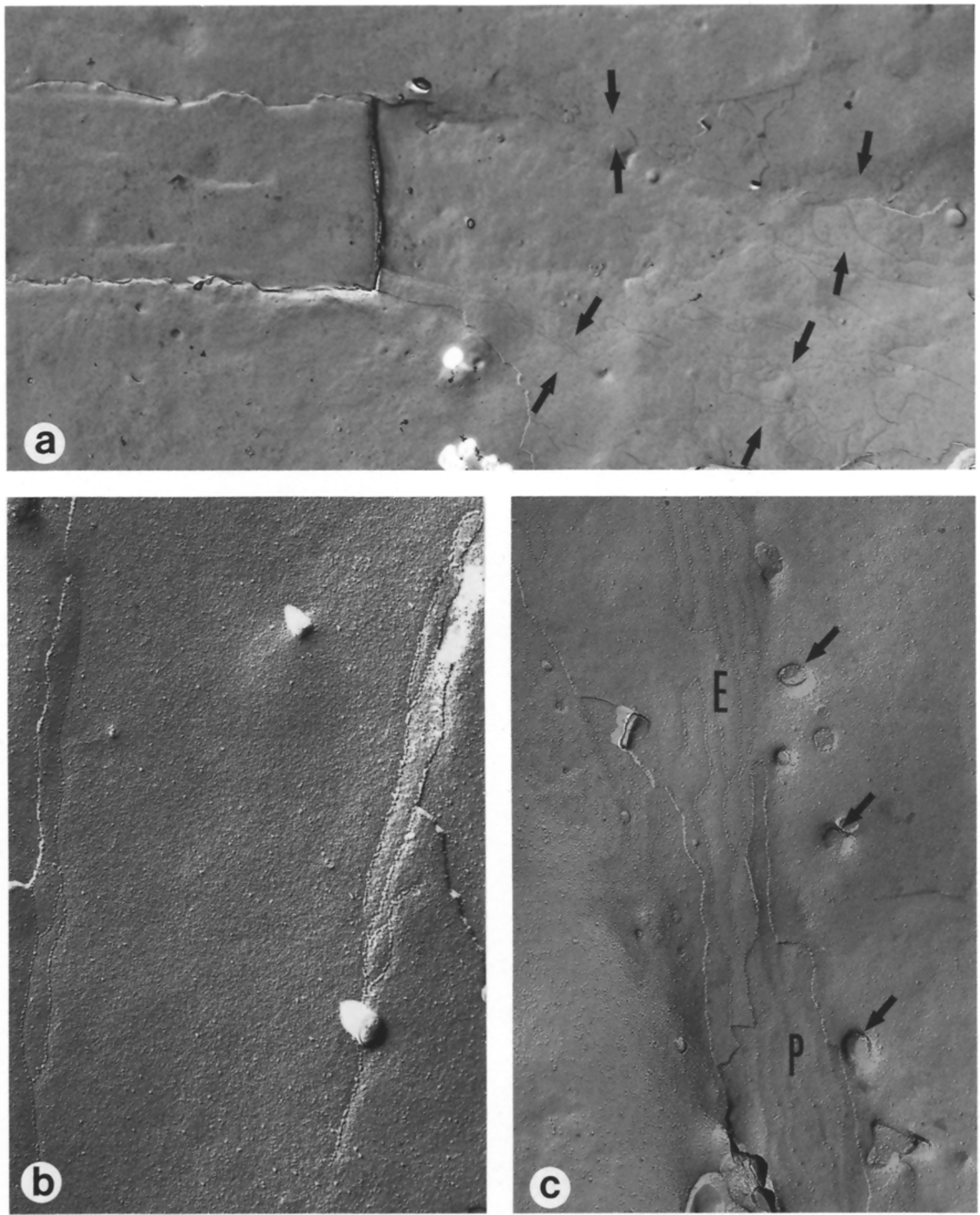

Fig. 5a-c. Electron micrographs of platinum-carbon replicas obtained by freeze-fracture. a Low power micrograph of a replica of cultured endothelial cells from spiral ligament showing tight junctions (arrows) at regions of cell overlap. $\times 18000$ b High magnification replica demonstrating two junctions longitudinally separating 3 cells. The intramembranous particles characteristic of the tight junction are evident (arrows) $\times 96200 \mathrm{c}$ Both the E- and P-faces are present in this replica from a stria vascularis endothelial culture. Also note that pinocytotic vesicles (arrows) are prevalent in stria vascularis and tend to be clustered near the tight junction (arrows). $\times 64500$

\section{Discussion}

In vivo morphologic studies of microvessels of the inner ear using tracers with light and electron microscopy have demonstrated that the capillaries in stria vascularis and spiral ligament have both shared and different characteristics. Both types of capillaries are classified as continuous, the endothelial cells joined together by tight junctions con- sisting of two to three rows of fibrils (Jahnke 1975). The endothelial cells of the spiral ligament, however, are impermeable to HRP (Duvall et al. 1971; Duvall and Klinker 1983; Gorgas and Jahnke 1974) and exhibit little pinocytosis. In contrast, strial endothelial cells exhibit a high degree of pinocytosis and are permeable to HRP via an endocytosis-exocytosis route (Sakagami et al. 1984). Based upon morphological evidence, Jahnke (1980) has proposed that 


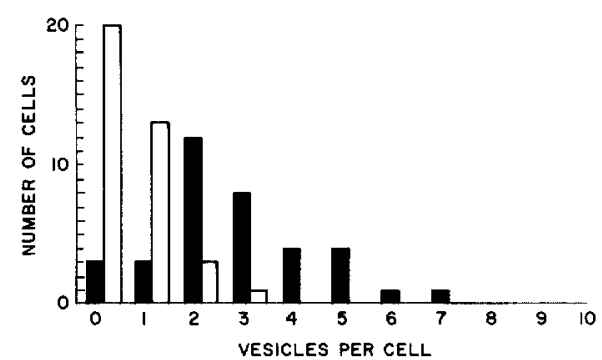

Fig. 6. A comparison of the frequency distributions of HRP-containing pinocytotic vesicles in cultured endothelial cells from stria vascularis (solid bars) and spiral ligament (open bars). The mean number of vesicles per stria vascularis endothelial cell $(2.8 \pm 1.6)$ is significantly greater $(p<0.001)$ than that of the spiral ligament $(0.6 \pm 0.76)$

endothelial cells of the spiral ligament are involved in the elaboration of perilymph and represent a blood-perilymph barrier analogous to the blood-brain barrier.

Capillaries of the stria vascularis differ further from those of the spiral ligament in that they are intraepithelial. Since stria vascularis epithelial cells are thought to be involved in the elaboration of endolymphatic fluid, the strial blood-endolymph barrier has been compared to blood-mes- enteric and blood-thymic barriers (Santos-Sacchi and Marovitz 1980).

Recent advances in cell culture of capillary endothelial cells demonstrate that cells from several different sources exhibit considerable growth if supplied with an appropriate substrate, such as collagen, gelatin or fibronectin (Folkman et al. 1979; Bowman et al. 1981, 1982; Davison et al. 1980) plus serum that has been specifically screened for their growth (Bowman 1982) or which has been supplemented with appropriate growth factors (Folkman et al. 1979; Buzney et al. 1983; Gitlin and D'Amore 1983). The addition of fetal calf serum to the culture medium apparently favors the growth of non-endothelial cells, possibly osteoblasts, osteoclasts, fibroblasts and inner ear intermediate cells (Maurizi et al. 1983). The approach taken in the present study of separating endothelial cells on Percoll gradients and cultivating them in plasma-derived, rather than fetal calf, serum resulted in pure capillary endothelial cell cultures. The most likely explanation for the effectiveness of the plasma-derived serum is that it contains reduced amounts of platelet-derived growth factor which is mitogenic to fibroblasts, smooth muscle cells and pericytes (Ross and Vogel 1978). Thus, plasma-derived serum supports endothelial cell growth while minimizing adventitious cell growth. The capillary endothelial cells from both stria vascularis and spiral ligament responded to heparin and endo-
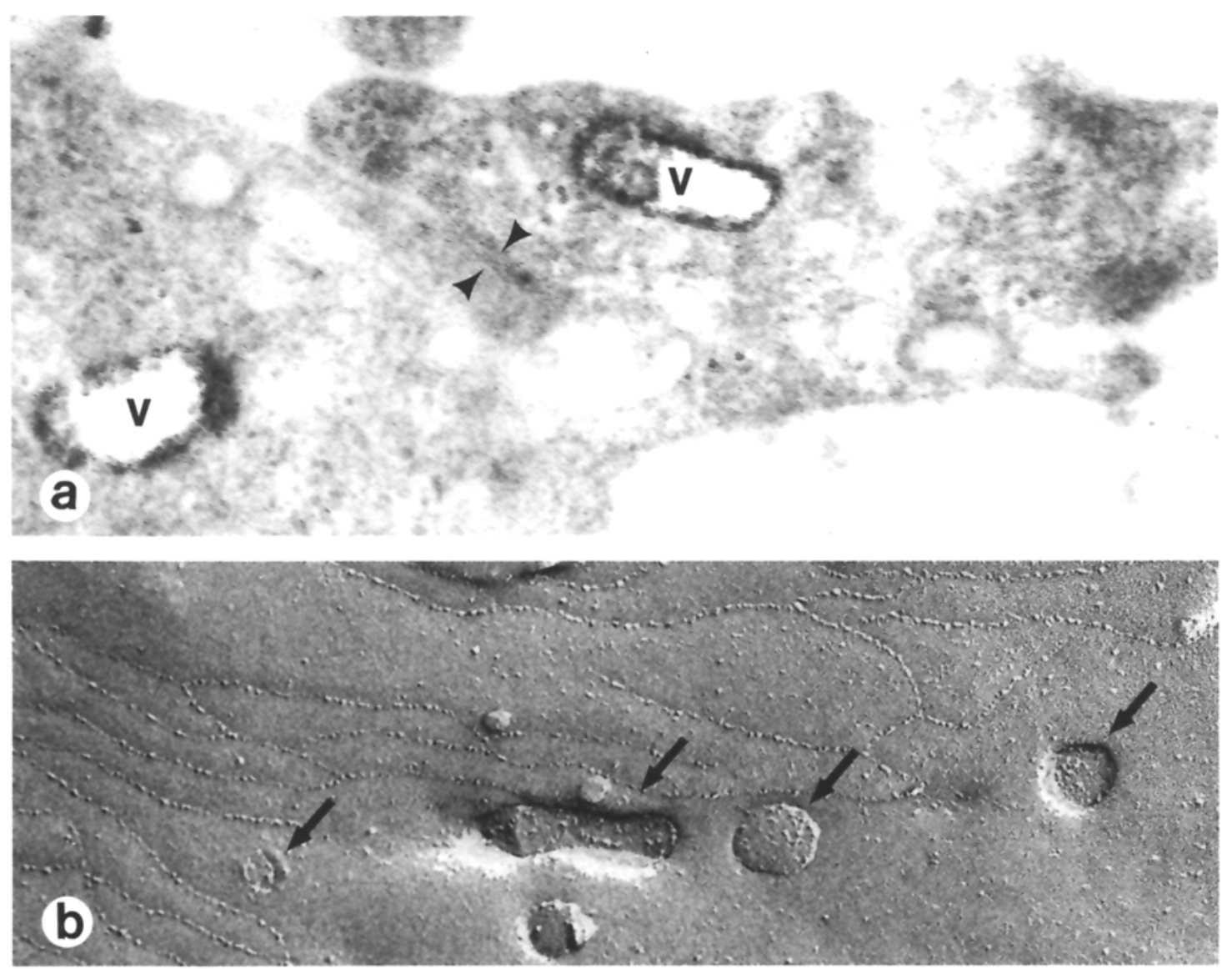

Fig. 7. a Electron micrograph of an HRP-treated, unstained stria vascularis endothelial culture. HRP did not penetrate the tight junctions (arrows) in either the stria vascularis or spiral ligament endothelial cells, indicating that both are tight to macromolecules of this size. However, during the $5 \mathrm{~min}$ exposure to HRP, evidence suggesting pinocytosis of HRP was observed. The HRP-containing vesicles $(v)$ were usually localized in the region of the tight junctional complexes. $\times 189000$ b Electron micrograph of a platinum replica of a stria vascularis endothelial cell at the same magnification as Fig. 7 a illustrating the tight junctional strands and the association of presumptive pinocytotic vesicles (arrows) with the junctional complex. $\times 189000$ 
thelial cell growth supplement by an increased growth rate, and this has also been reported for human large vessel endothelial cells (Thornton et al. 1983).

The retention of several characteristic endothelial properties by inner ear endothelial cells in primary culture suggests that these cells are suitable for morphologic and biochemical studies which may be directly applicable to the in vivo situation. The expression of Factor VIII-related antigen, angiotensin converting enzyme, and tight junctional complexes are important indications of the endothelial origin of these cells. The finding of numerous profiles of tight junctional complexes in freeze fracture replicas is particularly relevant to studies of barrier function. In addition to limiting the passage of substances between cells, tight junctions prevent lateral diffusion of membrane constituents, thereby creating asymmetry between the apical and basolateral membranes (van Deurs et al. 1982). The in vitro observation of greater amounts of pinocytotic vesicles in stria endothelial cells than spiral ligament endothelial cells grown under the same conditions is consistent with in vivo observations and suggests that this intrinsic specialized property of the cells is also retained in culture.

The blood-perilymph and blood-endolymph barriers provided by the capillary endothelial cells of the spiral ligament and stria vascularis, respectively, like other permeability barriers of the inner ear, play an active role in fluid and ionic microhomeostasis. Alteration of these barriers after exposure to ototoxic drugs may lead to sensorineural hearing loss. The mechanisms by which toxic substances gain entrance into the inner ear by crossing these blood barriers have not been elucidated. Therefore, an in vitro system for examining the characteristics of endothelial cells that form such barriers should provide a means to define the mechanisms by which such barriers are altered during injury and disease.

Acknowledgements. Supported by USPHS Research Grants No. 05065 and EY-03772, Program Project Grant NS 05785, and by the Deafness Research Foundation.

\section{References}

Auerbach R, Alby L, Grieves J, Lindren C, Morrissey LW, Sidky YA, Tu M, Watt SL (1982) Monoclonal antibody against angiotensin-converting enzyme: Its use as a marker for murine, bovine and human endothelial cells. Proc Natl Acad Sci USA $79: 7891-7895$

Bowman PD, Betz AL, Ar D, Wolinsky JS, Penney JB, Shivers RR, Goldstein GW (1981) Primary culture of capillary endothelium from rat brain. In Vitro 17:353-362

Bowman PD, Betz AL, Goldstein GW (1982) Primary culture of microvascular endothelial cells from bovine retina. In Vitro $18: 626-632$

Buzney SM, Massicotte SJ, Hetu N, Zetter BR (1983) Retinal vascular endothelial cells and pericytes. Differential growth characteristics in vitro. Invest Ophthalmol Vis Sci 24:470-480

Davison PM, Bensch K, Karasek MA (1980) Isolation and growth of endothelial cells from microvessels of newborn human foreskin in cell culture. J Invest Dermatol 75:316-321

Deurs $B$ van, Bülow $F$ von, Møllgàrd K (1982) Tight junctions: Architecture of plasma membranes at sites of cell-cell "fusion" in relation to paracellular permeability. Tokai J Exp Clin Med 7 Suppl: 197-202

Dorovini-Zis K, Bowman PD, Betz Al, Goldstein GW (1984) Hyperosmotic arabinose solutions open the tight junctions between brain capillary endothelial cells in tissue culture. Brain Res 302:383-386

Duvall AJ, Klinker A (1983) Macromolecular tracers in the mammalian cochlea. Am J Otolaryngol 4:400-410

Duvall AJ, Quick CA, Sutherland CR (1971) Horseradish peroxidase in the lateral cochlear wall. Arch Otolaryngol 93:304-316

Folkman J, Haudenschild CC, Zetter BR (1979) Long term culture of capillary endothelial cells. Proc Natl Acad Sci USA $76: 5217-5221$

Gimbrone MA, Cotran RS, Folkman J (1974) Human vascular endothelial cells in culture. Growth and DNA synthesis. J Cell Biol 60:673-684

Gitlin JD, D'Amore PA (1983) Culture of retinal capillary cells using selective growth media. Microvasc Res 26:74-80

Gorgas K, Jahnke K (1974) The permeability of blood vessels in the guinea pig cochlea. II. Vessels of the spiral ligament and the stria vascularis. Anat Embryol 146:33-42

Jaffe EA, Nachman RL, Becker CG, Minick CR (1973a) Culture of human endothelial cells derived from umbilical veins. J Clin Invest 52:2745-2756

Jaffe EA, Hoyer LW, Nachman RL (1973b) Synthesis of antihemophilic factor by cultured human endothelial cells. J Clin Invest 52:2757-2764

Jahnke K (1975) The fine structure of freeze-fractured intercellular junctions in the guinea-pig inner ear. Acta Otolaryngol (Suppl) (Stockh) 336:1-40

Jahnke K (1980) A blood-perilymph barrier. Arch Otorhinolaryngol 228:29-40

Larsen DM, Sheridan JD (1979) Structure of gap and tight junctions and transfer of small molecules from cell to cell in cultured bovine endothelial cells. Anat Rec 193:599

Maurizi M, Binaglia L, Donti E, Ottaviani F, Paludel G, Donti GV (1983) Morphological and functional characteristics of human temporal bone cultures. Cell Tissue Res 229:505-513

Pauli BU, Weinstein RS, Soble LW, Alroy J (1977) Freeze-fracture of monolayer cultures. J Cell Biol 72:763-769

Ross R, Vogel A (1978) The platelet-derived growth factor. Cell 14:203-210

Ryan US, Clements E, Habliston D, Ryan JW (1978) Isolation and culture of pulmonary artery endothelial cells. Tissue Cell $10: 535-554$

Sakagami M, Sano M, Tamaki H, Matsunaga T (1984) Ultrastructural study of the effect of acute hyper and hypotension on the stria vascularis and spiral ligament. Acta Otolaryngol (Suppl) (Stockh) 406:256-262

Santos-Sacchi J, Marovitz WF (1980) An evaluation of normal strial capillary transport using the electron-opaque tracers ferritin and iron dextran. Acta Otolaryngol (Stockh) 89:12-26

Simionescu M, Simionescu N, Palade GE (1975) Segmental differentiations of cell junctions in the vascular endothelium. The microvasculature. J Cell Biol 67:863-885

Thornton SC, Mueller SN, Levine EM (1983) Human endothelial cells : Use of heparin in cloning and long-term serial cultivation. Science 222:623-625

Wall RT, Harker LA, Quadracci LJ, Striker GE (1978) Factors influencing endothelial cell proliferation. J Cell Physiol 96:203-214

Zetter BR (1981) The endothelial cells of large and small blood vessels. Diabetes 30, Supp1 2:24-28

Accepted March 6, 1985 